\title{
Enzymic and Genetic Control of Polyphosphate Accumulation in Aerobacter aerogenes
}

\author{
By F. M. HAROLD \\ Department of Experimental Chemistry, Division of Research and \\ Laboratories, National Jervish Hospital at Denver, Colorado, U.S.A.
}

(Received 7 October 1963)

\begin{abstract}
SUMMARY
Addition of orthophosphate to Aerobacter aerogenes strain $\mathbf{A} 3(0)$ organisms previously subjected to phosphate starvation induced accumulation of inorganic polyphosphate within the organisms. With resumption of growth the polyphosphate was degraded and served as a source of nucleic acid phosphorus. During phosphate starvation the specific activity of polyphosphate kinase and inorganic polyphosphatase increased five- to tenfold while the amount of alkaline phosphatase increased 50 times. The results suggest that synthesis of polyphosphate kinase and alkaline phosphatase was subject to repression by exogenous orthophosphate. Two mutant strains blocked in polyphosphate accumulation were found to carry defects in the synthesis of these enzymes. Mutants of class Pn-1 contained normal amounts of all three enzymes, but repression of their synthesis was not annulled by phosphate starvation. Mutants of class Pn-2 contained no poly phosphate kinase. It is suggested that synthesis of polyphosphate kinase is controlled by two genes, a structural gene and a regulator gene; the latter gene also appears to control the synthesis of alkaline phosphatase and perhaps polyphosphatase. The patterns of polyphosphate accumulation under various nutritional conditions are discussed in relation to the amounts and activities of the enzymes of polyphosphate synthesis and degradation.
\end{abstract}

\section{INTRODUCTION}

Jeener \& Brachet (1944) discovered that addition of orthophosphate to phosphatestarved yeast resulted in rapid uptake of phosphate and accumulation of a basophilic substance within the organisms. Originally thought to be ribonucleic acid (RNA), the basophilic material was later identified as inorganic polyphosphate (Wiame, 1947; Schmidt, 1951). Its accumulation corresponded to the appearance of structures known as 'volutin granules'; both disappeared together when growth of the organisms was resumed. This basic pattern has since been described in various fungi and bacteria (Kuhl, 1960; Harold, 1962; Liss \& Langen, 1962; Smith, Wilkinson \& Duguid, 1954; Zaitseva, Belozerskii \& Novozhilova, 1960; Kaltwasser, 1962). The term 'polyphosphate overplus' is proposed to designate the accumulation of polyphosphate upon addition of orthophosphate to phosphate-starved organisms, in order to distinguish this from polyphosphate accumulation under other conditions of nutrient imbalance (Smith et al. 1954). The term corresponds to 'PolyphosphatÜberkompensation' as used by Liss \& Langen (1962).

The physiological basis of the polyphosphate overplus has remained obscure despite repeated investigation. Liss \& Langen (1962) found an increased rate of 
polyphosphate synthesis in yeast previously subjected to phosphate starvation and attributed this to an imbalance of phosphate uptake and utilization. In the present paper evidence will be offered to relate the polyphosphate overplus to the control of the enzymes of polyphosphate metabolism in wild-type Aerobacter aerogenes and in mutants of it which carry genetic defects in polyphosphate synthesis. Preliminary accounts of these results have been published (Harold, 1963a,b).

\section{METHODS}

Organisms. Aerobacter aerogenes strain A3 (0) was obtained from Professor J. F. Wilkinson. The isolation of auxotrophic mutants requiring uracil $\left(\mathrm{Sl}_{\mathrm{u}-}\right)$ and methionine $\left(0_{\text {met. }}\right)$ was described by Harold $(1963 c)$. Mutants defective in polyphosphate accumulation were isolated by a ${ }^{32} \mathrm{P}$-suicide technique (Harold \& Harold, 1963). These mutants, were of two types: (i) Pn-1 mutants which did not show the overplus effect but accumulated polyphosphate upon sulphur starvation; (ii) Pn-2 mutants which did not accumulate polyphosphate under any conditions. Most of the present experiments were conducted with the strains $1025 \mathrm{D}(\mathrm{Pn}-1)$ and $1023 \mathrm{C}$ (Pn-2) previously used.

Growth experiments. The bacteria were grown in $\mathrm{T}_{\text {subseript }}$ media as described earlier (Harold, 1963c; Harold \& Harold, 1963). This is a mineral medium containing sulphate as sole source of sulphur, glucose as carbon + energy source and

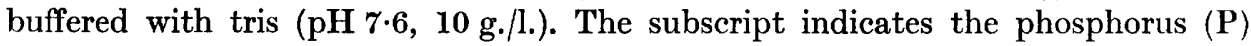
content as $\mu \mathrm{g}$. $\mathbf{P} / \mathrm{ml}$. All cultures were grown on a rotary shaker at $37^{\circ}$. The population density was normally about $10^{9}$ cells $/ \mathrm{ml}$.; multiplication was followed turbidimetrically at $600 \mathrm{~m} \mu$. Overnight cultures were grown in $\mathrm{T}_{230}$ medium; the organisms were then harvested, washed, and resuspended in fresh pre-warmed T medium containing orthophosphate and growth factors as described for the individual experiments. Samples were withdrawn periodically and the organisms centrifuged down. Samples intended for enzyme assay were washed with chilled tris buffer. Phosphorus analyses were performed on unwashed organisms. The fractionation and estimation of phosphorus compounds was described earlier (Harold, 1963c). The bulk of the polyphosphate was acid-insoluble polyphosphate; acid-soluble phosphate, when present, was measured separately and the two fractions added to give the amount of total inorganic polyphosphate.

Enzyme assay. Bacterial cells from $30 \mathrm{ml}$. culture were resuspended in $1 \mathrm{ml}$. tris buffer $(0 \cdot 1 \mathrm{M}, \mathrm{pH} 7 \cdot 0)$ in a plastic tube. Glass beads (Superbrite, Minnesota Mining and Manufacturing Co., Type $115 ; 0.50 \mathrm{~g}$.) were added, and the tube exposed for $20 \mathrm{~min}$. to sonic treatment in a Raytheon $10 \mathrm{Kc}$ oscillator cooled with ice water. The tubes were then centrifuged at $4^{\circ}$ for $10 \mathrm{~min}$. at $20,000 \mathrm{~g}$; the supernatant fluid was used for the estimation of polyphosphate kinase as described below, and for protein estimation by the biuret method (Layne, 1957).

Assay of polyphosphatase activity in these extracts gave variable results. As a rule, high activity was found only in extracts of bacterial cells which had been allowed to accumulate polyphosphate following phosphate starvation. This apparent production of polyphosphatase in response to polyphosphate accumulation was ultimately found to be an artifact: the enzyme is readily lost, apparently by adsorption to the glass beads, unless inorganic polyphosphate is present. Consequently, 
for the assay of polyphosphatase the bacterial cells were sonically treated in tris buffer containing polyphosphate (synthetic, chain length about $170,100 \mu \mathrm{g} . / \mathrm{ml} . \mathrm{P}$ ).

Polyphosphate kinase. This enzyme was assayed in crude extracts by a modification of the procedure described by Muhammed (1961). It had an obligatory requirement for $\mathrm{Mg}^{2+}$ and an optimum at about $\mathrm{pH}$ 7. Adenosine diphosphate (ADP) was inhibitory at concentrations above $2 \times 10^{-3} \mathrm{M}$, but polyphosphate itself had little effect at $15 \times 10^{-3} \mathrm{M}$. Each assay tube received $2 \mu$ mole acetyl phosphate- ${ }^{32} \mathrm{P}$, $2 \mu$ mole $\mathrm{MgCl}_{2}, 1 \cdot 5-5$ units acetokinase (Rose, 1955), 0.2 $\mu$ mole ADP, $25 \mu$ mole glycylglycine or tris buffer ( $\mathrm{pH} 7 \cdot 0$ ), and 0.05-0.10 ml. enzyme extract in a final volume of $0.33 \mathrm{ml}$. The tubes were incubated for $10 \mathrm{~min}$. at $37^{\circ}$. At that time, $0.25 \mathrm{ml}$. N-perchloric acid was added and then $0.50 \mathrm{ml}$. bovine serum albumin solution $(5 \mathrm{mg} . / \mathrm{ml}$.) to precipitate the polyphosphate formed. The precipitate was washed twice with $0.5 \mathrm{~N}$-perchloric acid, dissolved in $0.5 \mathrm{~N}-\mathrm{NaOH}$ and plated for counting. The course of the reaction was linear with time for 20 min. and proportional to enzyme concentration over the range of 0.02 to 4 units/tube. The unit is defined as that amount of enzyme which produces $0.01 \mu$ moles polyphosphate in $10 \mathrm{~min}$. The identity of the product was established by its behaviour in the standard fractionation scheme and by its complete lability to acid ( $\left.-\mathrm{HCl}, 15 \mathrm{~min} ., 100^{\circ}\right)$.

Polyphosphatase. The polyphosphatase activity of crude extracts had a broad $\mathrm{pH}$ optimum between 7 and 9. A requirement for $\mathrm{Mg}^{2+}$ was observed only in the presence of EDTA, but high concentrations of $\mathrm{KCl}$ (about $0.3 \mathrm{M}$ ) were necessary for maximal activity. No dialysable cofactors were detected. The assay of polyphosphatase was modified from that described by Muhammed, Rodgers \& Hughes (1959). Each assay tube received $100 \mu$ mole $\mathrm{KCl}, \mathbf{0} \cdot 25 \mu$ mole $\mathrm{MgCl}_{2}, 1 \cdot 6 \mu$ mole polyphosphate- ${ }^{32} \mathrm{P}, 10 \mu$ mole tris buffer ( $\mathrm{pH} 9$ ) and $0.05 \mathrm{ml}$. enzyme extract in a final volume of $0.30 \mathrm{ml}$. (the amount of polyphosphate introduced with the extract was neglected). The tubes were incubated at $37^{\circ}$ for $30 \mathrm{~min}$., then excess polyphosphate and protein were precipitated by adding $1.0 \mathrm{ml} .0 .5 \mathrm{~N}$-perchloric acid and $0.1 \mathrm{ml}$. bovine serum albumin (10 mg./ml.). The tubes were centrifuged and the supernatant fluids decanted. After addition of ammonium molybdate the ${ }^{32} \mathrm{P}$-orthophosphate was extracted with isobutanol (Weil-Malherbe \& Green, 1951), plated and counted. The hydrolysis of polyphosphate was linear with time for $60 \mathrm{~min}$. and proportional to the enzyme concentration over a wide range. A unit of polyphosphatase is defined as that amount of enzyme which liberates $0.01 \mu$ mole ${ }^{32} \mathrm{P}$-orthophosphate in $10 \mathrm{~min}$.

Alkaline and acid phosphatase. These enzymes were in general assayed with intact Aerobacter aerogenes organisms as described by Torriani (1960). For consistency, the unit is defined as that amount of enzyme which liberates $0.01 \mu$ mole orthophosphate from o-nitrophenyl phosphate in $10 \mathrm{~min}$.

Chemicals. Acetyl phosphate- ${ }^{32} \mathrm{P}$ was synthesized as described by Kornberg (1957), polyphosphate- ${ }^{32} \mathrm{P}$ by the method of Muhammed et al. (1959). Other reagents were purchased from Sigma Chemical Co. and the California Corporation for Biochemical Research.

\section{RESULTS}

The polyphosphate overplus in wild-type and mutant strains of Aerobacter aerogenes $A 3(0)$. Aerobacter aerogenes organisms in the logarithmic or the stationary phase of growth contained only traces of polyphosphate. When orthophosphate was added to organisms which had been incubated in phosphate-deficient medium 
for 3-4 hr dramatic accumulation of polyphosphate occurred, together with the appearance of microscopically visible volutin granules (Smith et al. 1954). Induction of this polyphosphate overplus was dependent upon protein synthesis during the starvation phase: no polyphosphate accumulation was observed when orthophosphate was added to strain A3(0) organisms subjected to phosphate starvation in absence of glucose or of sulphur, or to organisms of strain $0_{\text {met }}$. incubated in medium lacking orthophosphate and methionine. Protein synthesis was not, however, required for polyphosphate accumulation itself since chloramphenicol $(10 \mu \mathrm{g} . / \mathrm{ml}$.), sulphur deficiency or methionine deprivation had no effect once starvation was complete.

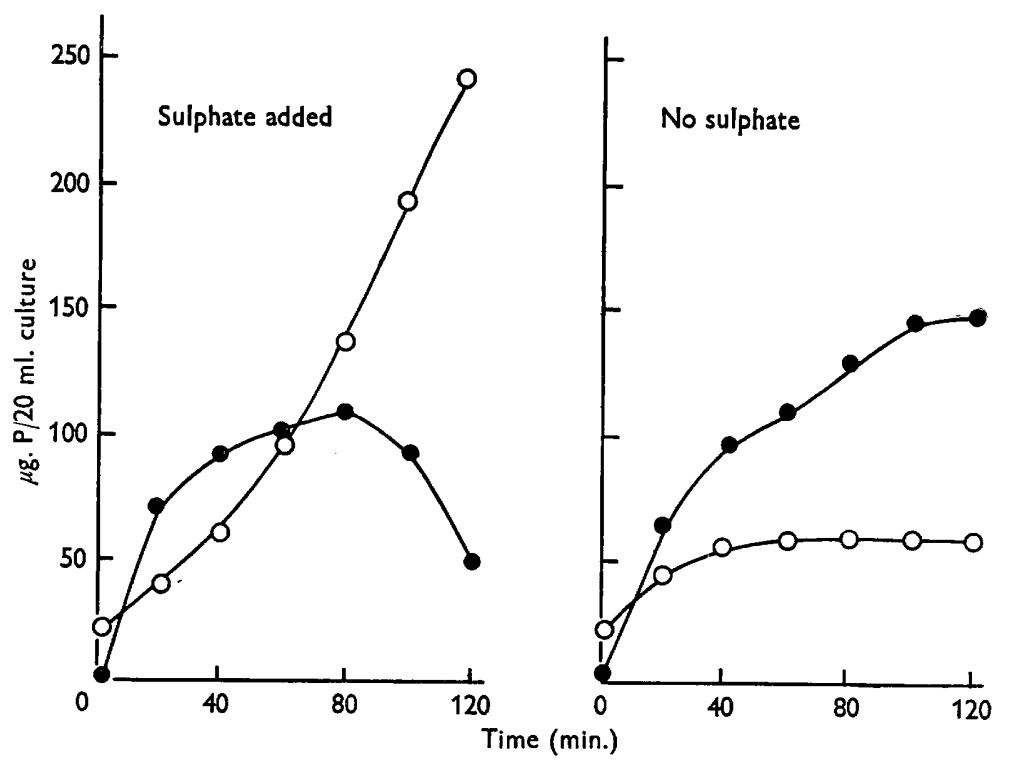

Fig. 1. The polyphosphate overplus in Aerobacter aerogenes strain $\mathbf{A 3}(0)$. The organisms were subjected to phosphorus starvation for $4 \mathrm{hr}$, collected, washed and resuspended in $\mathbf{T}_{0}$ medium with and without sulphate. Orthophosphate was added to both flasks at 0 min. 0 - Polyphosphate; $\mathrm{O}-\mathrm{O}$, total nucleic acids.

A typical experiment illustrating the accumulation of polyphosphate and its subsequent fate is shown in Fig. 1. Aerobacter aerogenes a 3(0) organisms were subjected to phosphorus starvation in $\mathrm{T}_{0}$ medium for $4 \mathrm{hr}$. The bacteria were then harvested, washed, and resuspended in $T_{100}$ medium, with and without sulphate. Both cultures rapidly accumulated polyphosphate and smaller amounts of nucleic acids. In the flask supplemented with sulphate, growth of the bacteria resumed and was accompanied by extensive nucleic acid synthesis and degradation of polyphosphate. In the sulphur-deficient culture growth was prevented, and a high polyphosphate concentration was maintained. The degradation of polyphosphate upon resumption of growth was shown to be a consequence of nucleic acid synthesis. In the presence of chloramphenicol protein synthesis and growth were inhibited, but nucleic acids accumulated within the bacteria and polyphosphate was concurrently degraded. In a typical experiment, organisms of the uracil-requiring mutant $\mathrm{Sl}_{\mathrm{u}}$. were subjected to phosphate starvation; the bacteria were then 
harvested and allowed to accumulate polyphosphate in radioactive $\mathbf{T}_{100}$ medium without uracil (to prevent nucleic acid synthesis). After $1 \mathrm{hr}$ the ${ }^{32} \mathrm{P}$-orthophosphate was diluted with excess unlabelled orthophosphate, and uracil + chloramphenicol $(10 \mu \mathrm{g} . \mathrm{ml}$. $)$ were added. Nucleic acid accumulated within the bacteria while the ${ }^{32} \mathrm{P}$-polyphosphate was degraded and the ${ }^{32} \mathrm{P}$ transferred to the nucleic acid fraction. These results are analogous to those described previously for the degradation of polyphosphate accumulated during nutrient deprivation (Harold, 1963c).

Mutants defective in polyphosphate accumulation showed quite a different pattern of phosphorus metabolism. Aerobacter aerogenes A3(0), Pn-1 and Pn-2 organisms were subjected to phosphorus starvation for $4 \mathrm{hr}$. The bacteria were then transferred to sulphur-deficient medium and ${ }^{32} \mathrm{P}$-orthophosphate $(100 \mu \mathrm{g} . / \mathrm{ml}$.) was added. As illustrated in Fig. 2, some nucleic acid was synthesized by all three strains but only strain A3(0) accumulated polyphosphate. Mutant and wild-type bacteria incorporated about equal amounts of ${ }^{32} \mathrm{P}$ into the orthophosphate and acid-soluble organic phosphate fractions.

Differential synthesis of enzymes of phosphate metabolism in Aerobacter aerogenes during phosphate starvation. From the results presented in the preceding section it is clear that the overplus phenomenon is a consequence of events which occur during the starvation phase and require protein synthesis. Clues to the nature of these events came from studies on the amount of polyphosphate kinase in wild-type and mutant Aerobacter aerogenes under various growth conditions. When bacteria of strain $\mathbf{A} \mathbf{3}(0)$ were incubated in phosphate-deficient medium, the optical density and protein content of the culture increased by about $50 \%$, and concurrently there was a marked increase in the specific activity of polyphosphate kinase. This increase in enzyme content was abolished by chloramphenicol and, in a methionine auxotroph, was dependent upon the presence of methionine (Fig. 3). The differential increase in the specific activity of polyphosphate kinase was induced specifically by phosphorus starvation: sulphur starvation and amino acid deprivation in auxotrophic mutants had no such effect. Upon addition of orthophosphate to phosphate-starved bacteria the differential rate of enzyme synthesis decreased until the value characteristic of growing bacteria (2-5 units/mg. protein) was attained. These results suggest that the synthesis of polyphosphate kinase is subject to repression by extracellular orthophosphate and thus proceeds at a higher differential rate during phosphate starvation.

The two polyphosphateless mutants exhibited clear defects in the synthesis of polyphosphate kinase. Organisms of strains A 3(0), Pn-1 and Pn-2 were grown on $\mathrm{T}_{230}$ medium and then transferred to $\mathrm{T}_{0}$ medium. As shown in Fig. 4, de-repression of polyphosphate kinase occurred only with strain $\mathbf{A} 3(0)$. Mutant strains of class Pn-1 contained normal amounts of enzyme (2-4 units/mg. protein) in growing organisms, but there was no increase in specific activity during phosphorus starvation. Mutants of class Pn-2 contained no detectable polyphosphate kinase under any nutritional conditions. No evidence was obtained for destruction of polyphosphate kinase in these extracts, nor for the presence of an inhibitor.

The effects of nutritional conditions on the amount of polyphosphatase paralleled those described for polyphosphate kinase. Bacteria from overnight cultures contained very little polyphosphatase (2-4 units enzyme/mg. protein) and incubation of such organisms in medium deficient in sulphur produced no increase in its amount. 


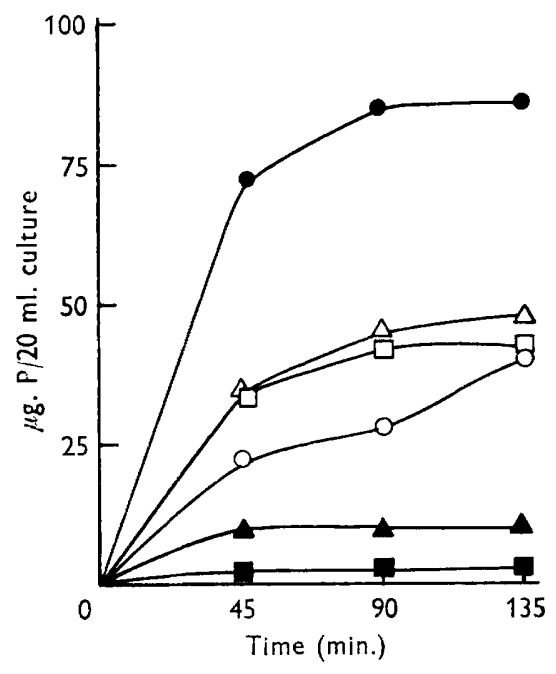

Fig. 2

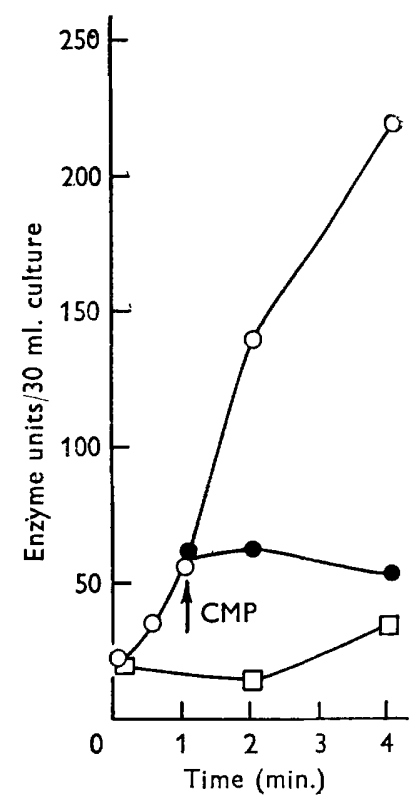

Fig. 3

Fig. 2. Accumulation of polyphosphate and nucleic acids in Aerobacter aerogenes strains A3 (0), Pn-1 and Pn-2. The bacteria were subjected to phosphorus starvation for $4 \mathrm{hr}$, collected, washed and resuspended in $\mathrm{T}_{0}$ medium without sulphate. ${ }^{32} \mathrm{P}$-orthophosphate was added to all flasks at $0 \mathrm{~min}$. Closed symbols, polyphosphate; open symbols, nucleic acids. O, O, Strain A 3(0); $\Delta, \triangle$, mutant Pn-1; $\square, \square$, mutant Pn-2.

Fig. 3. Synthesis of polyphosphate kinase in Aerobacter aerogenes strain $\mathrm{O}_{\text {met. }}$ during phosphate starvation. Washed organisms were suspended in $T_{0}$ medium at $0 \mathrm{hr}$, and the culture distributed among three flasks. Flask no. $1(\mathrm{O}-\mathrm{O})$ was supplemented with methionine (30 $\mathrm{g} . / \mathrm{ml}$.); no. 2 ( $\square-\square)$ received no methionine; no. 3 (०-○) received methionine but chloramphenicol (CMP; $10 \mu \mathrm{g}$./ml.) was added after $1 \mathrm{hr}$.
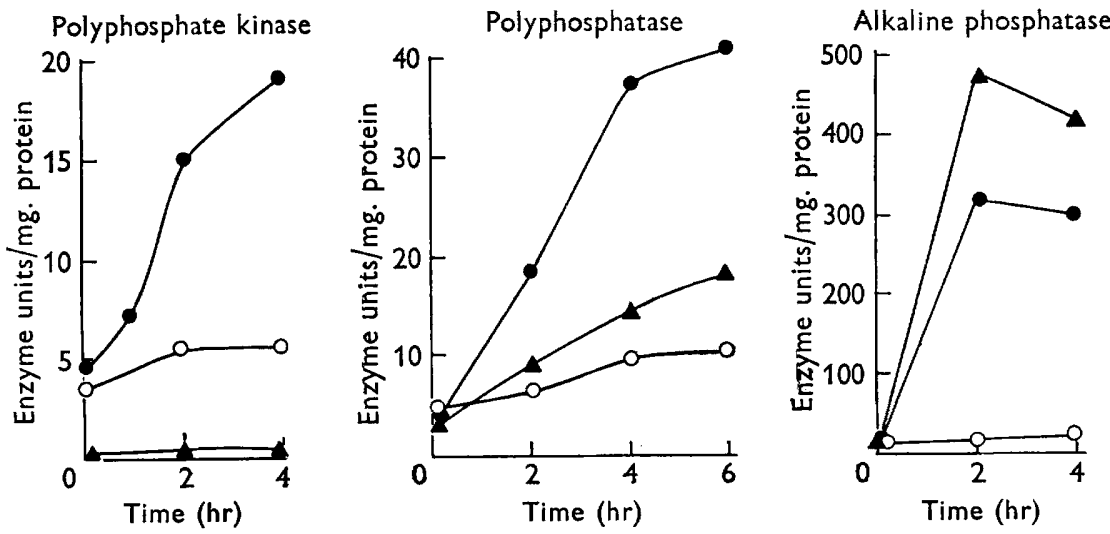

Fig. 4. Effect of phosphate starvation on the amounts of polyphosphate kinase, polyphosphatase and alkaline phosphatase in Aerobacter aerogenes strains A3(0), Pn-1 and Pn-2. Bacteria from an overnight culture were collected, washed and resuspended in

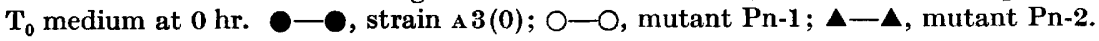


Bacteria harvested during the logarithmic phase of growth contained 6-10 units enzyme/mg. protein. During incubation in phosphate-deficient medium, a substantial increase in the specific activity of polyphosphatase occurred in strain $\mathbf{A} \mathbf{3}(0)$ organisms and, to a lesser degree, in Pn-2 organisms; the specific activity of polyphosphatase in strains of class Pn-1 was not affected (Fig. 4). The production of polyphosphatase required protein synthesis and thus presumably reflected differential synthesis of the enzyme, but repression upon subsequent addition of orthophosphate was not unequivocally demonstrated.

Differential synthesis of alkaline phosphatase during phosphate starvation in Escherichia coli was demonstrated by Torriani (1960) and by Horiuchi, Horiuchi \& Mizuno (1959), and shown to be due to repression of the synthesis of this enzyme by exogenous orthophosphate. It therefore seemed of interest to examine whether the synthesis of alkaline phosphatase and of the enzymes of polyphosphate metabolism might be under joint genetic control. As shown in Fig. 4, phosphate starvation induced extensive synthesis of alkaline phosphatase in organisms of Aerobacter aerogenes strains A 3(0) and Pn-2, but not in organisms of strain Pn-1. The amount of acid phosphatase was unaffected.

\section{DISCUSSION}

Accumulation of inorganic polyphosphate in micro-organisms is generally associated with nutritional conditions unfavourable to growth. Two quite distinct procedures for the induction of polyphosphate accumulation in Aerobacter aerogenes were described by Smith et al. (1954). On the one hand, polyphosphate accumulates when growth of the organisms ceases because of lack of certain essential nutrients, e.g. in sulphur starvation. Deposition of polyphosphate under these conditions has been shown to be due primarily to the cessation of nucleic acid synthesis while assimilation of phosphate from the medium continues (Harold, $1963 \mathrm{c}$ ). On the other hand, polyphosphate accumulates upon addition of orthophosphate to a phosphate-starved culture. This phenomenon, for which the term 'polyphosphate overplus' is proposed, is the subject of the present paper. The patterns of polyphosphate accumulation under these two nutritional conditions are quite different. Polyphosphate accumulation due to nutrient deprivation is relatively slow, and is prevented by concurrent nucleic acid synthesis as well as by other environmental factors which accelerate polyphosphate degradation (Harold \& Sylvan, 1963). The polyphosphate overplus is more rapid and is quite independent of nucleic acid synthesis (Fig. 1) and of changes in the composition of the medium. The physiological basis of these differences appears to reside in the amount of polyphosphate kinase. Wild-type $\boldsymbol{A}$. aerogenes organisms normally contain a low concentration of polyphosphate kinase, and the rate of polyphosphate synthesis in vivo during nutrient deprivation agrees well with that calculated from the amount of enzyme present. During phosphate starvation the specific activity of polyphosphate kinase increases up to tenfold, and a corresponding increase in the rate of polyphosphate accumulation is observed when orthophosphate is made available to the starved organisms. It thus appears that the rate of polyphosphate synthesis is directly proportional to the amount of polyphosphate kinase within the organisms. Results with mutants blocked in polyphosphate accumulation (Harold \& Harold, 1963) support this conclusion. Aerobacter aerogenes mutants of class Pn-2 lack polyphosphate 
kinase, and do not accumulate polyphosphate under any conditions. Hence polyphosphate kinase catalyses the main, if not the only, reaction responsible for polyphosphate synthesis. Mutants of $\boldsymbol{A}$. aerogenes class Pn-1 contain normal amounts of polyphosphate kinase and are therefore capable of slow polyphosphate accumulation when subjected to nutrient deprivation. However, repression of the synthesis of this enzyme is not annulled by phosphate starvation and hence no polyphosphate overplus occurs upon addition of orthophosphate.

The intracellular concentration of polyphosphate must be a function of the rates of synthesis and of degradation. From the present results and from those reported earlier (Harold, 1963c), it seems clear that polyphosphate degradation is coupled to nucleic acid synthesis. Except under special nutritional conditions (Harold \& Sylvan, 1963), little polyphosphate degradation occurs until growth and nucleic acid synthesis resume. The molecular basis underlying the control of polyphosphate breakdown is unknown. Studies with cell-free extracts have provided evidence for four possible routes for the mobilization of inorganic polyphosphate: transfer of phosphate to ADP by reversal of polyphosphate kinase (Kornberg, 1957); transfer of phosphate to adenosine monophosphate (Winder \& Denneny, 1957); direct phosphorylation of hexoses by polyphosphate (Dirheimer \& Ebel, 1962; Szymona, Szymona \& Kulesza, 1962); hydrolytic degradation to orthophosphate by inorganic polyphosphatase. The limited information available from work with intact organisms (Hughes \& Muhammed, 1962; Harold, 1962) seems to favour hydrolysis as the chief route of polyphosphate degradation. Should this prove to be the case in Aerobacter aerogenes, an explanation will be required for the accumulation of polyphosphate in organisms subjected to phosphate starvation despite their elevated content of polyphosphatase (Fig. 4).

It remains to consider the genetic control of polyphosphate metabolism. During phosphate starvation differential synthesis of alkaline phosphatase, polyphosphate kinase and polyphosphatase occurs in wild-type Aerobacter aerogenes; the synthesis of the first two enzymes is repressed when orthophosphate is restored. Two mutations were found to affect this metabolic region. Mutants of class Pn-1 contain all three enzymes but repression of their synthesis is not annulled by phosphate starvation. Mutants of class Pn-2 lack polyphosphate kinase, but synthesize alkaline phosphatase and a small amount of polyphosphatase in phosphate-deficient medium. It is thus reasonable to postulate two genes, a regulator gene which controls the synthesis of all three enzymes (Pn-1) and a structural gene for polyphosphate kinase (Pn-2). The diminished formation of polyphosphatase in Pn-2 shows that this simple picture is no more than a first approximation. Nevertheless, the finding that these three enzymes form a unit of genetic regulation suggests that they constitute also a physiological unit, functionally concerned with phosphate storage (Harold, $1963 b)$.

The author wishes to thank Miss Norma Layher for excellent technical assistance. This work was supported in part by a research grant (AI 03568) from the U.S. Public Health Service. 


\section{REFERENCES}

Dirheimer, G. \& Ebel, J. P. (1962). Demonstration of a polyphosphate-glucose-phosphotransferase in Corynebacterium xerosis. C.R. hebd. Séanc. Acad. Sci., Paris, 254, 2850.

Harold, F. M. (1962). Depletion and replenishment of the inorganic polyphosphate pool in Neurospora crassa. J. Bact. 83, 1047.

HAROLD, F. M. (1963a). Enzymatic basis of polyphosphate accumulation in phosphatestarved Aerobacter aerogenes. Bact. Proc. 1963, p. 125.

Harold, F. M. (1963b). Regulatory mechanisms in the metabolism of inorganic polyphosphate in Aerobacter aerogenes. Les Méchanismes de Regulation des Activités Cellulaires chez les Microorganismes, Colloques int. Cent. natn. Rech. scient. no. 107.

Harold, F. M. $(1963 c)$. Accumulation of inorganic polyphosphate in Aerobacter aerogenes. I. Relationship to growth and nucleic acid synthesis. J. Bact. 86, 216.

Harold, F. M. \& Sylvan, S. (1963). Accumulation of inorganic polyphosphate in Aerobacter aerogenes. II. Environmental control and the role of sulphur compounds. J. Bact. 86, 222.

Harold, R. L. \& Harold, F. M. (1963). Mutants of Aerobacter aerogenes blocked in the accumulation of inorganic polyphosphate. J. gen. Microbiol. 31, 241.

Horiuchi, T., Horiuchi, S. \& Mizuno, O. (1959). A possible negative feedback phenomenon controlling formation of alkaline phosphomonoesterase in Escherichia coli. Nature, Lond. $183,1529$.

Hughes, D. E. \& Muhammed, A. (1962). The metabolism of polyphosphate in bacteria. Acides Ribonucleiques et Polyphosphates, Colloques Internationaux du Centre National de la Recherche Scientifique, no. 106, 591. Paris: Editions du C.N.R.S.

Jeener, R. \& Brachet, J. (1944). Recherches sur l'acide ribonucléique des levures. Enzymologia, 11, 22.

Kaltwasser, H. (1962), Die Rolle der Polyphosphate im Phosphatstoffwechsel eines Knallgasbakteriums (Hydrogenomonas). Arch. Microbiol. 41, 282.

Kornberg, S. R. (1957). Adenosine triphosphate synthesis from polyphosphate by an enzyme from Escherichia coli. Biochim. biophys. Acta, 26, 294.

KuHl, A. (1960). Die Biologie der kondensierten anorganischen Phosphate. Ergebn. Biol. $23,144$.

LAYNE, E. (1957). Spectrophotometric and turbidimetric methods for measuring proteins. In Methods in Enzymology. Ed. by S. P. Colowick \& N. O. Kaplan, vol. 3, p. 447. New York: Academic Press.

Liss, E. \& Langen, P. (1962). Versuche zur Polyphosphat-Überkompensation in Hefezellen nach Phosphatverarmung. Arch. Microbiol. 41, 383.

Muhammed, A. (1961). Studies on biosynthesis of polymetaphosphate by an enzyme from Corynebacterium xerosis. Biochim. biophys. Acta, 54, 121.

Muhammed, A., Rodgers, A. \& Hughes, D. E. (1959). Purification and properties of a polymetaphosphatase from Corynebacterium xerosis. J. gen. Microbiol. 20,482 .

Rose, I. A. (1955). Acetate kinase of bacteria. In Methods in Enzymology. Ed. by S. P. Colowick \& N. O. Kaplan, vol. I, p. 591. New York: Academic Press.

SснміDт, G. (1951). The biochemistry of inorganic pyrophosphates and metaphosphates. In Phosphorus Metabolism. Ed. by W. D. McElroy \& B. Glass, vol. I, p. 443. Baltimore: Johns Hopkins Press.

Smith, I. W., Wilkinson, J. F. \& Duguid, J. P. (1954). Volutin production in Aerobacter aerogenes due to nutrient imbalance. J. Bact. 68, 450.

Szymona, M., Szymona, O. \& Kulesza, O. (1962). On the occurrence of inorganic polyphosphate hexokinase in some microorganisms. Acta microbiol. pol. 11, 287.

Torriani, A. (1960). Influence of inorganic phosphate on the formation of phosphatases by Escherichia coli. Biochim. biophys. Acta, 38, 460.

Weil-Malmerbe, H. \& Green, R. H. (1951). The catalytic effect of molybdate on the hydrolysis of organic phosphate bonds. Biochem. J. 49, 286. 
Wiame, J. M. (1947). Étude d'une substance polyphosphorée, basophile et metachromatique chez les levures. Biochim. biophys. Acta, 1, 234.

Winder, F. G. \& Denneny, J. M. (1957). The metabolism of inorganic polyphosphate in Mycobacteria. J. gen. Microbiol. 17, 573.

Zaitseva, G. N., Belozerskit, A. N. \& Novozhilova, L. P. (1960). Effect of calcium ion on nitrogen and phosphorus metabolism in Azotobacter vinelandii. Microbiology Moscore. (English edn.), 29, 254. 